\title{
Non-traumatic spinal intradural haematoma: a rare case of paralysis following abciximab for ST elevation acute coronary syndrome
}

\author{
Geoffrey R Wong, ${ }^{1}$ Daniel J Scherer, ${ }^{1}$ Adam J Nelson, ${ }^{1}$ Matthew lan Worthley ${ }^{2}$
}

${ }^{1}$ Department of Cardiology, Royal Adelaide Hospital, Adelaide, South Australia, Australia

${ }^{2}$ Cardiovascular Research Centre, Royal Adelaide Hospital, Adelaide, South Australia, Australia

\section{Correspondence to} Dr Geoffrey R Wong, geoffrey.wong@adelaide.edu. $\mathrm{au}$

Accepted 19 April 2016

\section{CrossMark}

To cite: Wong GR, Scherer DJ, Nelson AJ, et al. BMJ Case Rep Published online: [please include Day Month Year] doi:10.1136/ bcr-2016-215616

\section{DESCRIPTION}

We present a case of a previously healthy 64-year-old man who presented initially with chest pain and inferior ST elevation acute coronary syndrome. Primary angiography revealed minor left coronary disease and an occluded proximal right coronary artery. Oral loading doses of aspirin $300 \mathrm{mg}$ and prasugrel $60 \mathrm{mg}$ were prescribed. Given significant thrombus burden, intravenous weight-adjusted glycoprotein $\mathrm{IIb} / \mathrm{III}$ inhibitor abciximab $(0.25 \mathrm{mg} / \mathrm{kg})$ and unfractionated heparin (70 units $/ \mathrm{kg}$ ) boluses were given and a 6 Fr Export (Medtronic, Minnesota, USA) aspiration catheter restored thrombolysis in myocardial infarction III flow. Two resolute integrity (Medtronic, Minnesota, USA) drug-eluting stents were successfully deployed. Chest pain and ECG changes resolved, and abciximab infusion $(0.125 \mu \mathrm{g} / \mathrm{kg} / \mathrm{min})$ was continued for $12 \mathrm{~h}$. The next morning, the patient developed severe lower back pain with urinary retention, loss of anal sphincter tone, bilateral lower limb areflexia, grade 0 power deficits and T12 sensory level. Urgent MRI of the spine demonstrated an extensive T7-T12 intradural haematoma with spinal cord compression on T2-weighted sagittal (figure 1) and axial sequences (figure 2). Digital subtraction angiography did not reveal any underlying vascular malformation. The patient underwent urgent neurosurgical exploration

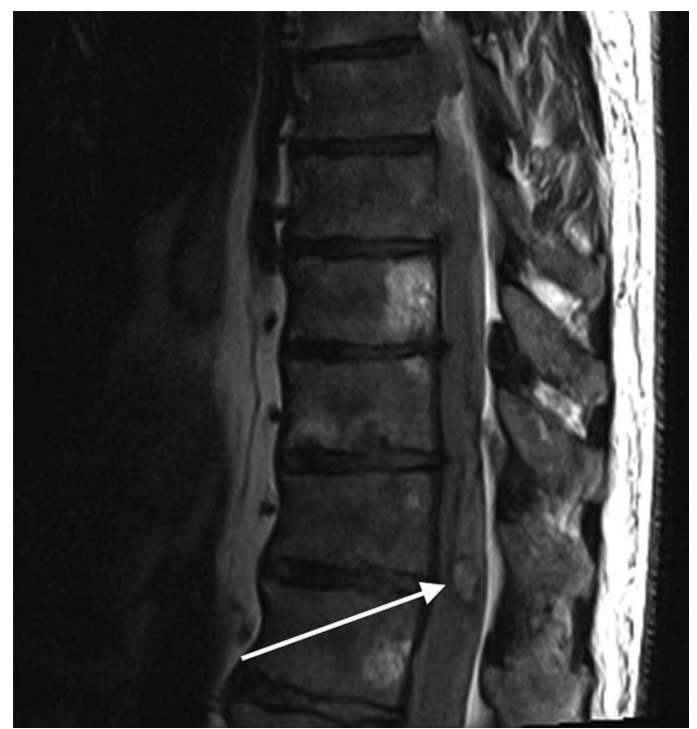

Figure 1 Thoracolumbar spine MRI T2-weighted sequence. Sagittal view showing extensive hyperintense acute intradural haematoma from T7 to T12 (white arrow).

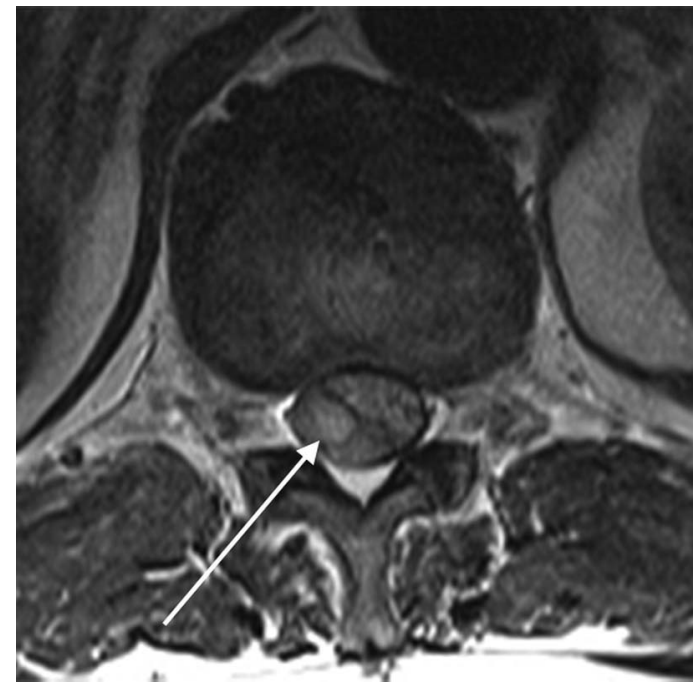

Figure 2 Thoracolumbar spine MRI T2-weighted sequence. Axial view showing large hyperintense acute intradural haematoma (white arrow) with significant spinal cord compression.

and evacuation of the intradural haematoma, thoracic laminectomy and posterior durotomy. Repeat MRI 2 weeks later showed no residual haematoma (figure 3), and although paraplegia persisted, aspirin was cautiously restarted. The patient was transferred for rehabilitation and remarkably, after 5 months of intensive therapy, ambulated independently with a frame, regained bladder and bowel function, and was discharged home.

Non-traumatic spinal intradural extramedullary haematomas (SIEH) are extremely rare. The majority require emergency attention as they can rapidly progress to spinal cord compression. In the largest series of 101 cases of spinal subdural haematomas, the thoracolumbar region was most frequently affected, without a gender predominance. ${ }^{1}$ Causes of non-traumatic SIEH include iatrogenic (lumbar puncture, spinal anaesthesia/surgery), anticoagulation, haematological disorders, vascular malformations, tumours and an idiopathic aetiology. ${ }^{2}$ Only 41 cases due to anticoagulation have been reported in the literature in patients on warfarin or low molecular weight heparin. Typical clinical features are sudden onset back or radicular pain with paraplegia and bowel or bladder paralysis. Meningism and headache may be the initial symptoms with predominantly subarachnoid bleeding. MRI is the gold standard for diagnosis of spinal haematomas. The classical finding in intradural haematomas is a 


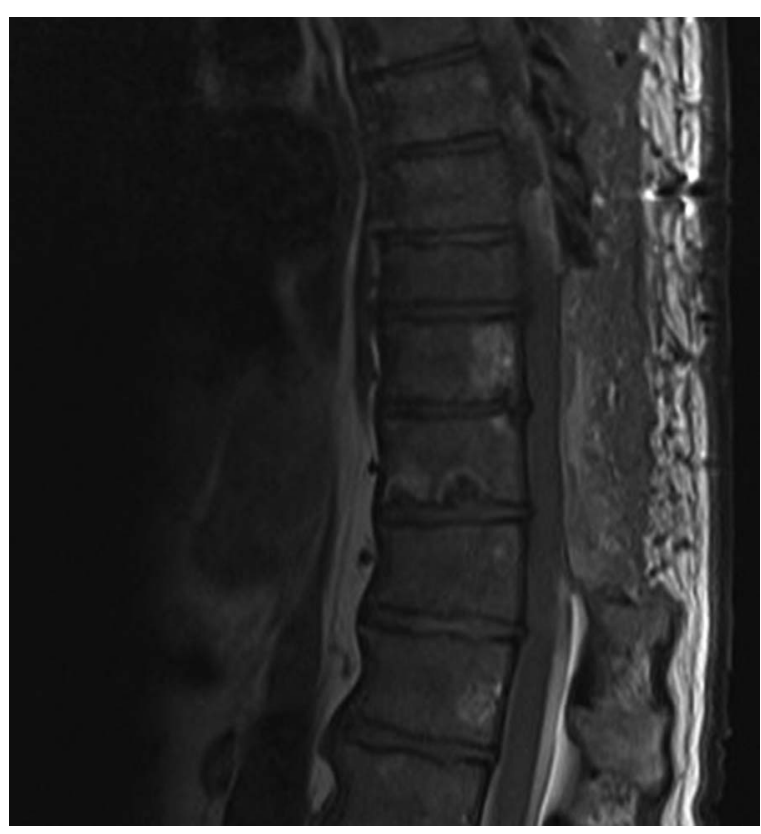

Figure 3 Thoracolumbar spine MRI T2-weighted sequence. Sagittal view demonstrating postoperative resolution of haematoma and cord compression.

concave loculated delineation of isointensity compared with the spinal cord on T1-weighted images, and variable signal hyperintensity on T2-weighted images. ${ }^{3}$ This is in contrast to epidural spinal haematomas, which appear broad-based and convex. Prompt neurosurgical evacuation and decompression is essential as prognosis is inversely related to duration of cord compression. ${ }^{1}$

This is the first report of a rare but serious complication in the era of potent antithrombotic therapies in ACS. While these agents have led to significant recent improvements in cardiovascular outcomes, the competing bleeding risk may drive adverse events. Clinicians should be vigilant in monitoring these patients, particularly those at higher risk.

\section{Learning points}

- Acute back pain with clinical red flags such as neurological deficit should be urgently investigated. MRI is the imaging modality of choice for spinal cord pathology.

- Acute non-traumatic spinal intradural extramedullary haematomas are a rare cause of spinal cord compression in patients on potent anticoagulant and antithrombotic therapies, such as abciximab, ticagrelor and prasugrel, used in the management of acute coronary syndrome.

- Spinal intradural haematoma with spinal cord compression should be managed with prompt neurosurgical evacuation of the clot, to improve patient outcomes and neurological recovery.

Twitter Follow Adam Nelson at @ajnelson

Contributors MIW was responsible for study concept and design. All the authors were responsible for analysis and interpretation of the data. GRW, DJS and AJN contributed to drafting of the manuscript. GRW, MIW and AJN contributed to critical revision.

Competing interests None declared.

Patient consent Obtained.

Provenance and peer review Not commissioned; externally peer reviewed.

\section{REFERENCES}

1 Domenicucci M, Ramieri A, Ciappetta $P$, et al. Nontraumatic acute spinal subdural hematoma. J Neurosurg 1999;91:65-73.

2 Bruce-Brand RA, Colleran GC, Broderick JM, et al. Acute nontraumatic spinal intradural hematoma in a patient on warfarin. J Emerg Med 2013;45:695-7.

3 Hausmann O, Kirsch E, Radu E, et al. Coagulopathy induced spinal intradural extramedullary haematoma: report of three cases and review of the literature. Acta Neurochir (Wien) 2001;143:135-40.

Copyright 2016 BMJ Publishing Group. All rights reserved. For permission to reuse any of this content visit

http://group.bmj.com/group/rights-licensing/permissions.

BMJ Case Report Fellows may re-use this article for personal use and teaching without any further permission.

Become a Fellow of BMJ Case Reports today and you can:

- Submit as many cases as you like

- Enjoy fast sympathetic peer review and rapid publication of accepted articles

- Access all the published articles

- Re-use any of the published material for personal use and teaching without further permission

For information on Institutional Fellowships contact consortiasales@bmjgroup.com

Visit casereports.bmj.com for more articles like this and to become a Fellow 